\title{
DELAMINATION RESISTANCE OF LAMINATE MADE WITH VBO MTM46/HTS PREPREG
}

\author{
Piotr CZARNOCKI*, Kamila CZAJKOWSKA** \\ *Institute of Aeronautics and Applied Mechanics, Warsaw University of Technology, Nowowiejska 24, 00-665 Warsaw, Poland \\ *Institute of Aviation, Aleja Krakowska 110/114, 02-256 Warsaw, Poland \\ pecz@meil.pw.edu.pl, kamila.czajkowska@ilot.edu.pl
}

received 4 May 2015, revised 28 October 2015, accepted 29 October 2015

\begin{abstract}
A laminate made with the Vacuum Bag Only (VBO) prepregs can be cured out of autoclave. Because of low curing pressure such a process can result in deterioration of laminate mechanical properties. They can be significantly lower than those displayed by the autoclave cured ones. The resistance against delamination can be among the most affected. Since this property is a week point of all the laminates it was of particular interest. Delamination resistance of unidirectional laminate made from VBO MTM46/HTS(12K) prepreg was in the scope of the presented research and the critical values of the Strain Energy Release Rates and the Paris-type equations corresponding to Mode I, Mode II and Mixed-Mode I/II static and cyclic loadings, respectively, were determined.
\end{abstract}

Key words: Delamination, VBO Prepregs

\section{INTRODUCTION}

Vacuum Bag Only (VBO) prepregs are relatively new semifinished raw products for manufacturing laminate primary airframe parts. Such prepregs can be cured out of autoclave with the use of ovens only, Due to this the related investment and production costs can be lowered since autoclaves and autoclave curing can be eliminated form manufacturing process. However processing conditions of such prepregs are not well established yet, especially in the case of MTM46/HTS(12K) one. For this prepreg the manufacturer suggested curing process should be carried at $130^{\circ} \mathrm{C}$ and under $90 \mathrm{kPa}$ vacuum pressure. Such a relatively low curing pressure, comparing to $800 \mathrm{kPa}$ for prepregs cured in autoclaves, results in more difficult control of void formation and can generate problems with obtaining porosity in the range accepted by an aircraft industry, i.e. below $1 \%$. The essential difference in the porosity control can be explained with the temperature-pressure-time diagrams overlapped with void size diagrams shown in Fig.1.

a

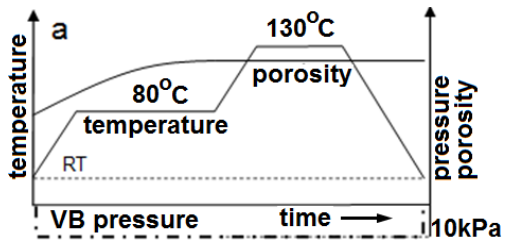

$\mathrm{b}$

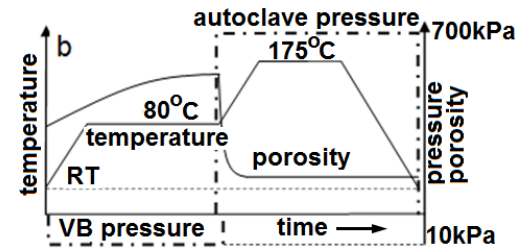

Fig. 1. Temperature-pressure-time diagrams overlapped with void size diagrams for: a) VBO prepregs, b) autoclave cured prepregs
An autoclave pressure of 8 bars, Fig.1a can suppress void formation and reduce size of already formed ones while vacuum pressure created in vacuum bag does not produce such an effect and reduction of porosity can only be achieved by evacuation of the air entrapped inside a laminate with the help of air evacuation ducts, Fig.2, that were produced in the course of specific impregnation process (Bai, 2013).
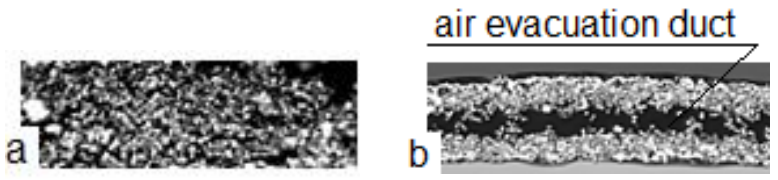

Fig. 2. Structure of uncured prepregs; a) autoclave cured a) VBO- air evacuation ducts are indicated

Resistance of laminates against delamination is their wellknown weak point, in general, and porosity can make it even worst. In the case of laminates made with MTM46/HTS(12K) prepreg pores can be easily formed because of low curing pressure. The MTM46/HTS(12K) prepreg has often been considered as a potential candidate for manufacturing structural components of composite airframes. However, material data available in the literature and these provided by the manufacturer do not offer sufficient amount of information concerning the mentioned property. Therefore investigations of delamination resistance under static and cyclic loadings of a laminate made with MTM46/HTS(12K) prepreg were undertaken and the obtained results are presented in this paper. The critical values of the Strain Energy Release Rate (SERR) G $G_{l c} G_{\| c}$ and $G / / l c$, and the Paris-type equations were determined for Mode I, Mode II and Mixed-Mode I/II static and cyclic loadings for a unidirectional laminate. For this purpose the beam type laminate specimens were used. While Mode I, Mode II, Mixed-Mode 1/II (ASTM D5528-12, ASTN D6671-13) static tests and fatigue Mode I (ASTM D6615-97) test have been standard- 
ised, there is no standard procedure for Mode II and Mixed-Mode I/II fatigue tests, yet. Therefore, when necessary more detailed information on the test procedures and data reduction methods were provided.

\section{EXPERIMENTAL}

\subsection{Specimens}

The specimens were cut out from $300 \mathrm{~mm} \times 200 \mathrm{~mm} \times 3.2 \mathrm{~mm}$ laminate plates consisted of 22 prepreg plies. To assure an appropriate ply compaction a debulking procedure was carried out for each four consecutive ply placements. The applied curing temperature-time and pressure-time profiles are shown in Fig. 3.

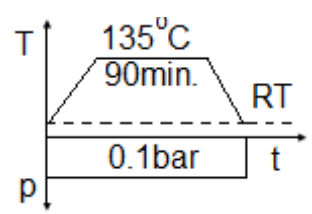

Fig. 3. Temperature-pressure-time curing profile

To facilitate delamination onset and propagation $0.013 \mathrm{~mm}$ Teflon tape delamination starters were embedded in the middle plane of specimens. The specimen geometry and loading configurations are shown in Fig. 4. Both the static and cyclic Mixed-Mode tests were run for constant ratio of the SERR components $\mathrm{G}_{\|} / \mathrm{G}_{\mathrm{I}}=$ 0.724 .

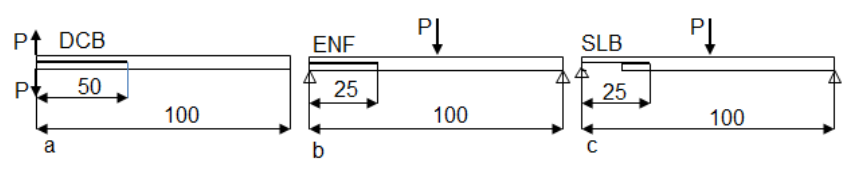

Fig. 4. Specimen geometry and loading configurations for: a) Mode I, b) Mode II and c) Mixed-Mode I/II tests

\subsection{Testing}

All the tests were run with the help of INSTRON Electro Puls E3000 testing machine equipped with $1000 \mathrm{~N}$ load cell.

Static tests were run under displacement control with cross head speed $0.5 \mathrm{~mm} / \mathrm{s}$ and $0.75 \mathrm{~mm} / \mathrm{s}$ for Mode I, Mode II and Mixed-Mode I/II tests, respectively.

Fatigue tests were run with the use of the same equipment and under displacement control with the cyclic frequency $5 \mathrm{~Hz}$, the cycle parameter $R=0.1$ and initial values of $\mathrm{G}_{\mathrm{I}}, \mathrm{II}, \mathrm{l} / \mathrm{I} \max =0.5 \mathrm{G} \mathrm{I}, \mathrm{II}, \mathrm{l} / \mathrm{I} \mathrm{c}$.
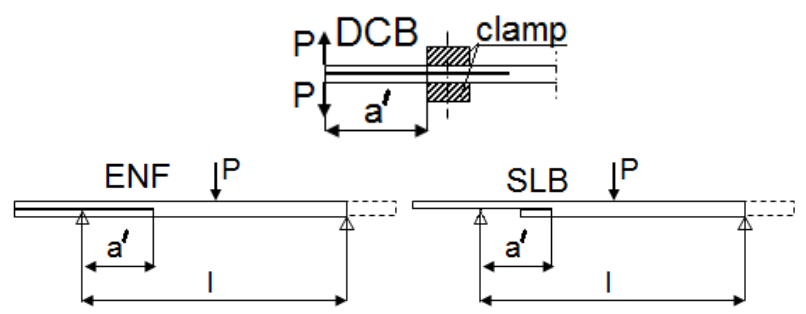

Fig. 5. Specimens configurations for experimental determination of $\mathrm{C}\left(\mathrm{a}^{\prime}\right)$ relationships for $\mathrm{DCB}$, ENF and SLB specimens
In the case of both the static and fatigue tests a current delamination length, a, was calculated based on specimen compliance changes $C\left(a^{\prime}\right)$. These relationships were determined experimentally for each specimen separately and then used for this particular specimen to calculate delamination length based on the compliance value.

Determination of $\mathbf{C}\left(\mathbf{a}^{\prime}\right)$ relationship. To determine $\mathrm{C}\left(\mathrm{a}^{\prime}\right)$ relationship specimens with oversize delamination starters were manufactured, Fig.5 and delamination growth, a', was simulated. End Notch Flexure (ENF) and Single Leg Bending (SLB) specimens were gradually shifted in jigs to the right, Fig.5, to change a' values. For each specimen and for each a' value a specimen compliance was calculated and C(a') relationship was constructed. In the case of Double Cantilever Beam (DCB) specimens changes in a' values could be obtained with the help of clamps which would be tighten in appropriate positions to obtain desired a' values. The range of a' changes was adjusted in such a way that the obtained $\mathrm{C}\left(\mathrm{a}^{\prime}\right)$ relationships covered ranges of expected delamination growths in the real tests, i.e. $25 \leq a^{\prime} \leq 50$ for ENF and SLB specimens, and $50 \leq a^{\prime} \leq 80$ for DCB ones.

\subsection{Data reduction}

\section{Static tests:}
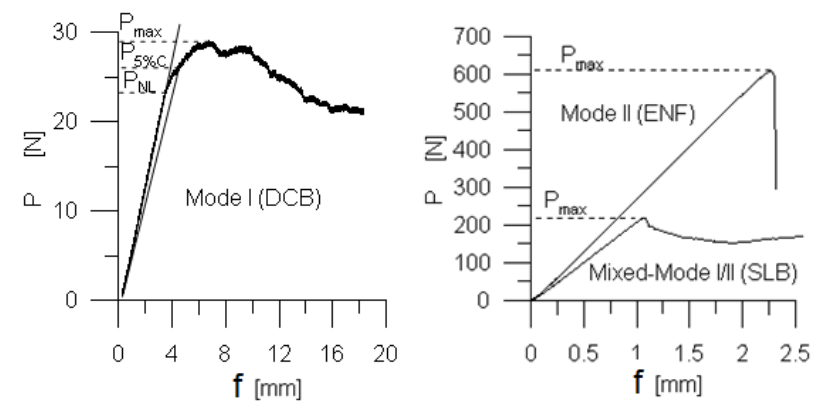

Fig. 6. Typical plots of $P(f)$ relationships obtained from Mode I, Mode II and Mixed-Mode I/II static tests

Mode I test. ASTM D5528 recommends three data reduction methods: Modified Beam Theory (MBT), Compliance Calibration, (CC) and Modified Compliance Calibration (MCC). The critical values of the SERR according to these methods were calculated with the help of (1-3), respectively.

$$
\begin{aligned}
G_{I c} & =\frac{3 P f}{2 B(a+\Delta)}, \\
G_{I C} & =\frac{n P f}{2 B a}, \\
G_{I C} & =\frac{3 P^{2} C^{2 / 3}}{2 A_{1} B h},
\end{aligned}
$$

where: $B$ - specimen width, $P$ - load, $f$ - relative displacement of loading points, $h$ - half of specimen thickness, $\Delta$ - value determined experimentally by generating a least square plot of the cube root of compliance $\sqrt[3]{C}$, as a function of delamination length, $C$ - compliance of the cracked beam (ratio of the loading point displacement over the applied load), $n$ - slope of the straight line drawn through the data generated from a least square plot of log $\left(f_{i} / P_{i}\right)$ versus $\log \left(a_{i}\right), A_{1}$ - slope of the straight line drawn through the data generated from least squares plot of delamina- 
tion length normalized by specimen thickness, a/h, as a function of the cube root of compliance, $\sqrt[3]{C}$.

In addition, three different values of force, $P$, and corresponding values of $\mathrm{f}$ could be considered, i.e. $P_{N L}$, corresponding to the onset of nonlinearity of $P(f)$ plot, $P_{5 \% C}$, corresponding to the intersection of $P(f)$ plot with the straight line representing 1.05 of initial compliance and $P_{\text {max }}$, being maximum force value recorded during the test under consideration, see Fig. 6 .

Mode II test. The tests were run according to ASTM D D6671 standard recommendations. The critical values of the SERR could be calculated with formula (4) or (5). For the presented research formula (4) was used

$G_{I I c}=\frac{9 a_{0}^{2} P_{\max } f_{\max }}{2 B\left(2 L^{3}+3 a_{0}^{3}\right)}$

or alternatively

$G_{I I C}=\frac{3 m P_{\max }^{2} a^{2}}{2 B}$,

where $m$ is the slope of experimentally determined $C(a)$ relationship of the form $C(a)=A+m a^{3}$

Mixed-Mode test. For this test SLB loading configuration was used. Although this configuration is not recommended by the ASTM D6671 standard, nevertheless it was chosen because an application of the same loading configuration for the cyclic tests was intended due to convenient jig design. For this loading configuration the critical value of the SERR is given by (6) (Szekrenyes, 2010).

$$
G_{I / I I C}=\frac{21 a^{2} P f}{2 B\left(7 a^{3}+2 L^{3}\right)} \text {. }
$$
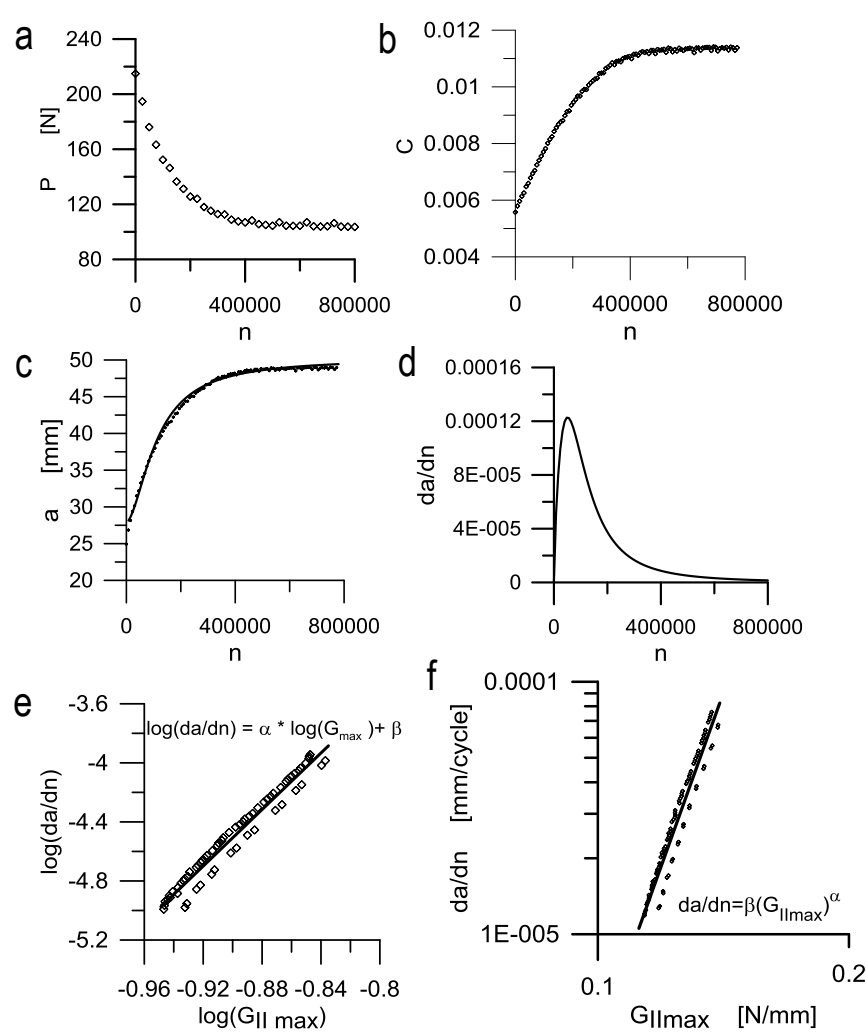

Fig. 7. Data reduction procedure: (a) raw data, (b) compliance vs. cycle elapsed, (c) a(n) obtained with the help of (7), (d) $d a / d n(n)$ obtained based on (7) and (c), (e) auxiliary graph for determining coefficients of the Paris relationship, (f) sought Paris relationship
Fatigue tests. They aimed determination of Paris like relationships of the form $d a / d n=f\left(G_{\max }\right)$. The tests have not been standardized yet except Mode I fatigue test for which recommendations are given in ASTM D6115 standard. Where possible, this standard was considered for Mode II and Mixed-Mode I/II data reduction procedures. The major departures from the standard recommendation was done regarding determination of $d a / d n=$ $f(n)$ relationships. The details of the applied procedure can be found in Czajkowska et al., (2014). The standard procedure recommends the 7-point polynomial piecewise approximation of $d a / d n=f(n)$ relationship. For the purpose of the presented research this relationship was not obtained by the pricewise approximation but the entire set of $a_{i}$ and corresponding $n_{i}$ values was considered and correlated with the help of sigmoidal function of the form (7):

$$
a=\frac{\alpha \beta+\gamma n^{\delta}}{\beta+n^{\delta}},
$$

where: $\alpha, \beta, \gamma, \delta$ are parameters needed to fit the curve

Delamination length, a, for each recorded $n$-th cycle was calculated with the help of previously determined $C\left(a^{\prime}\right)$ relationship and corresponding pairs of $P_{i}$ and $f_{i}$ values. Since all the test were carried out under displacement control all the nominal deflection values, $f$, remained constant during each test.

\subsection{Results}

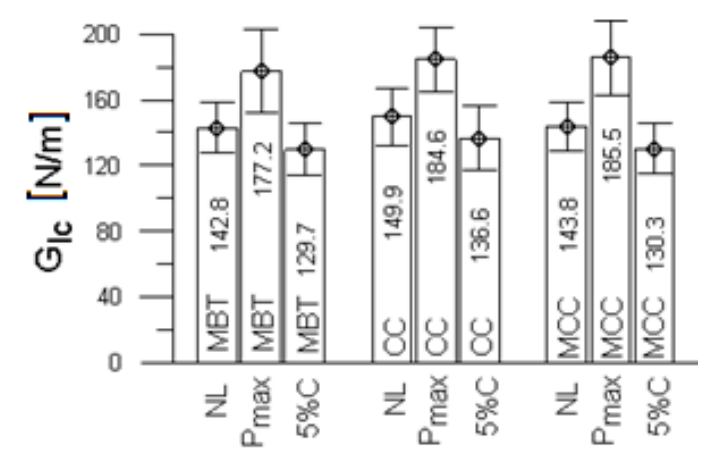

Fig.8. Values of Glc calculated according to MBT, CC and MCC data reduction procedures assuming $P_{C}$ equal to $P_{N L}, P_{\max }$ and $P_{5 \% C}$ for each of the method used.(For explanation of symbols and subscripts see eqs.1-3 and Fig. 6, respectively). For each $G_{I c}$ value $95 \%$ confidence interval has been marked

Bar diagram in Fig. 8 presents initiation values of $G_{I c}$ calculated according to the three data reduction methods defined by eqs.1-3. For each data reduction method three different values of force, $P_{c}$, initiating delamination propagation were assumed. They were, (see Fig. 6):

- force corresponding to the onset of nonlinearity of $P(f)$ relationship, $P_{N L}$;

- force corresponding to the intersection point of $P(f)$ plot and the straight line representing $5 \%$ increase in the compliance $C=f / P, P_{5 \% C}$

- force corresponding to the maximum of $P(f)$ plot, $P_{\text {max }}$.

Analysing the results used to construct bar diagram in Fig. 8 one could noticed that the most narrow $95 \%$ confidence interval as well as standard deviation were obtained for $P_{c}=P_{5 \% C}$.

Plot in Fig.9 presents variation of the critical values of the SERR, $G_{c i}$, corresponding to the initiation of delamination propa- 
gation as a function of the mode mixity defined with the phase angle $\Psi$ (8), ( $\Psi=40.4^{\circ}$ corresponds to $\left.\mathrm{G}_{\|} / \mathrm{G}_{\mid}=0.724\right)$. $\mathrm{G}_{\mid c i}$ was calculated for $P_{c}=P_{5 \% C}$ while $\mathrm{G}_{\| \mathrm{lci}}$ and $\mathrm{G} / / \mathrm{llci}$ for $P_{c}=P_{\max }$.

$\Psi=\operatorname{atan} \sqrt{\frac{G_{I I}}{G_{I}}}$.

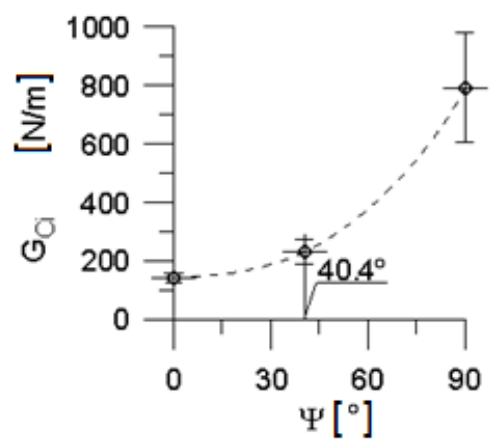

Fig. 9. Resistance against delamination under Mode I, Mode II and Mixed-Mode I/II static loadings. The plot represents the initiation values of $G_{c i}$ versus phase angle $\Psi$ (8) with $95 \% \% \mathrm{Cl}$ marked

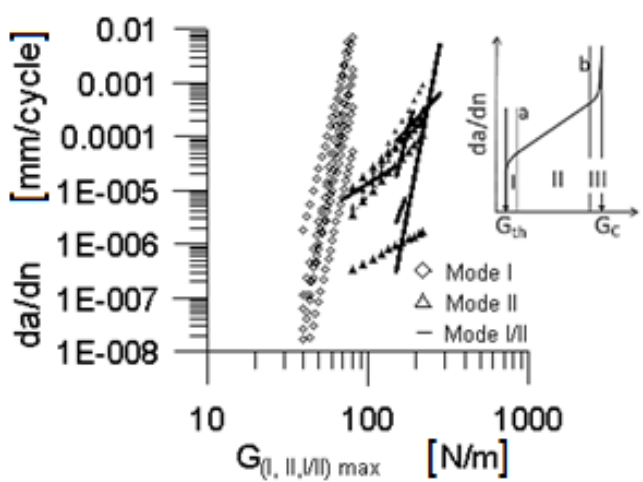

Fig.10. Paris relationships $d a / d n=\beta\left(G_{\max }\right)^{\alpha}$ (region II, on the pictogram) for Mode I, Mode II and Mixed-Mode I/II loadings for MTM46/HTS(12K) laminate. Scatter of the results for each loading mode reflects the scatter of the laminate delamination resistance for the loading mode under consideration

Experimental results of fatigue tests are shown in Figs.10 and 11. for region II and I (see pictograms in Figs 10 and 11) of $d a$ / $d n\left(G_{\max }\right)$ relationship respectively. From plots in Fig.10 one could conclude that the most dangerous was Mode I loading. This founding corresponds with the results of the static tests showing the lowest resistance against delamination under static Mode I loading. Also, one could notice that for Mode I loading the rate of delamination propagation was more sensitive to the changes in $G$ than for the two other loading Modes. The lowest sensitivity to such changes was noticed for Mode II. Unexpected relation between the delamination propagation rates was noticed for Mode II and Mixed-Mode I/II. In the aspect of GIlc and GI/llc values, (Fig. 9 ), one would expect that the rate of delamination propagation under Mode II cyclic loading should be lower than that under Mixed-Mode loading, which was not the case.

Typical $d a / d n\left(G_{\max }\right)$ relationships for low values of $G_{\max }$ (region I) are shown in Fig.11. It could be noticed that for Mode II and Mixed-Mode I/II loadings possibly threshold values of $G_{\max }$, (for which delamination did not grow), could be indicated. This was not the case for Mode I loading for which a delamination growth rate $d a / d n<10-7$ cycle/mm was observed even for $G_{\text {max }}<50 \mathrm{~N} / \mathrm{m}$. (It was decided to terminate the tests at this delamination growth rate).

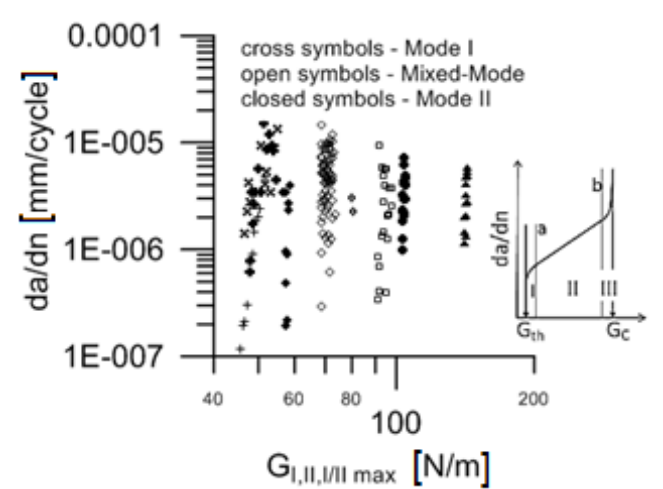

Fig. 11. Examples of $d a / d n\left(G_{\max }\right)$ data for Mode I, Mode II and Mixed-Mode I/II fatigue loadings for low $G_{\max }$ values, (region I on the pictogram). Possible threshold values of $\mathrm{G}_{\| \max }$ and $\mathrm{G}_{/ \| \operatorname{lmax}}$ could be noticed

\subsection{Delamination resistance of MTM46/HTS laminates in perspective}

For comparison purpose the critical values of the SERR for Mode I, Mode II and Mixed-Mode I/II loadings for common autoclave-cured laminates of aircraft grade are given in Tab. 1 together with the corresponding properties of MTM46/HTS.

Tab. 1. Interlaminar toughness of laminates

\begin{tabular}{|l|l|l|l|}
\hline laminate & Glc N/m & Gllc N/m & \multicolumn{1}{|c|}{ Gl/llc N/m } \\
\hline MTM46/HTS & 142 & 793 & 230 \\
\hline $3501-6 / A S 4$ & $200[5]$ & $525[5]$ & - \\
\hline $8552 / / M 7$ & $230[6]$ & $1334[13]$ & $280[10]$ \\
\hline $977-3 / / M 7$ & $154[12]$ & $670[9]$ & - \\
\hline $914 C / T 300$ & $112[11]$ & $220[11]$ & $220[11] \mathrm{G}_{\|} / \mathrm{G}_{\mathrm{I}}=1$ \\
\hline
\end{tabular}

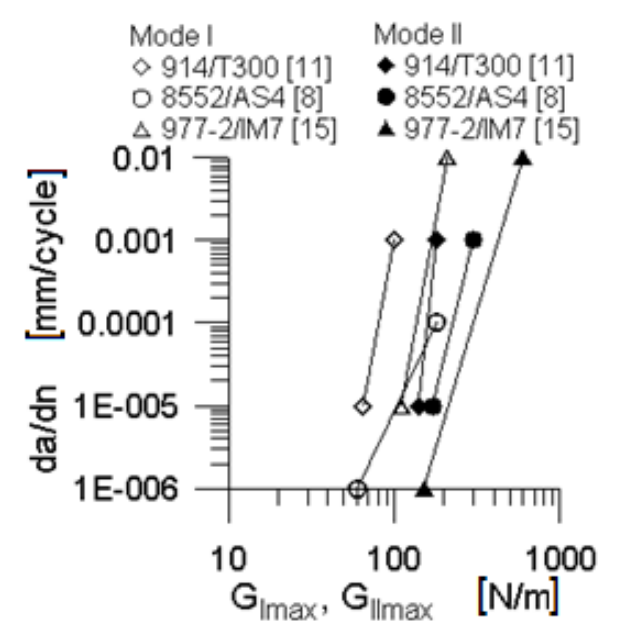

Fig. 12. Resistance against delamination of 914/T300, 8552/AS4 and 977-2/IM7 laminates under cyclic Mode I and Mode II loadings. Data reproduced from (Meziere and Michel, 2000; Hiley, 2000; Stelzer at al., 2013) 
Comparison of fatigue data is difficult because there is scant reference to this data in generally accessible literature. Furthermore, the published data are in the form of plots only, and coefficients of Paris equations corresponding to these plots are not provided at all or are not complete. For this reason the plots shown in Fig. 12 are not very accurate representation of the cited literature data and should be regarded as same approximations of the original plots, only.

\section{CONCLUSIONS}

Comparing delamination resistance of MTM46/HTS laminate subjected to static and cyclic loadings against delamination resistance of aircraft grade laminates made with autoclave cured prepregs one could conclude that:

- VBO MTM46/HTS laminate displayed higher delamination resistance under static and cyclic loadings than laminate made with $914 \mathrm{C} / \mathrm{T} 300$ prepreg containing non- toughened resin.

- in the case of autoclave cured laminates containing toughened resins their delamination resistance was significantly higher than that of the laminate tested.

- using out-of-autoclave curing process one could obtain laminates displaying similar delamination resistance as those for which autoclave curing process was used assuming that the laminates under consideration were impregnated with the resin systems of similar toughness.

\section{REFERENCES}

1. ASTM D5528-12 Standard Test Method for Mode I Interlaminar Fracture Toughness of Unidirectional Fiber-Reinforced Polymer Matrix Composites

2. ASTM D6115-97 Standard Test Method for Mode I Fatigue Delamination Growth Onset of Unidirectional Fiber-Reinforced Polymer Matrix Composites

3. ASTM D6671-13 Standard Test Method for Mixed Mode I-Mode II Interlaminar Fracture Toughness of Unidirectional Fiber Reinforced Polymer Matrix Composites

4. Bai J. (ed.) (2013), Advanced fibre-reinforced polymer (FRP) compositesfor structural application, Woodhead Pu. Ltd.

5. Becht G. J., Gillespie J. W. (1989), Numerical and Experimantal Evaluation of the Mode III Interlaminar Fracture Toughness of Composite Materials, Polymer Composites, 10, 293-303.

6. Czabaj M. W., Ratcliffe J. (2012), Comparison of Intralaminar and Interlaminar Mode-I Fracture Toughness of Unidirectional IM7/8552 Graphite/Epoxy Composite, NACA raport NF 16762-15094.

7. Czajkowska K., Czarnocki P, Lorenc Z. (2014), Interlaminar Mode II Toughness of Unidirectional CF-Epoxy Laminates Made of out of Autoclave Prepregs, Key Engineering Materials, 598, 45-50.

8. Hiley M. (2000), Delamination between multi-directional ply interfaces in carbon-epoxy composite under static and fatigue loadings, Fracture of Polymers, Composites and Adhesives, ESIS Publication 27, 41-72.

9. Kim R. Y. (2001), Polymer matrix composite (PMC) damage tolerance and repair technology, Report No. UDR-TR-2001-00041.

10. Lander J. K., Kawashita L. F, Allegri G, Hallett S. R, Wisnom M. R., (2010), A cut ply specimen for the determination of mixedmode interlaminar fracture toughness, 14th European Conference on Composite Materials, 1-11.

11. Meziere Y., Michel L. (2000), Mixed-Mode delamination Failure criteria in Carbon Fibre/Composite under Quasi-Static and Cyclic Loadings, Fracture of Polymers, Composites and Adhesives, ESIS Publication 27, 97-110.

12. Murri B., (2011), Effect of Data Reduction and Fiber-Bridging on Mode I Delamination Characterization of Unidirectional Composites, Proceedings of the American Society for Composites 26th Annual Technical Conference/2nd Joint US-Canada Conference on Composites.

13. Paris I., Minguet P. J., O'Brien T. K. (2003), Comparison of Delamination Characterisation for IM7/8552 Composite Woven and Tape Laminates, ASTM STP 1436, 372-390.

14. Stelzer S., Jones R., Brunner A. J. (2013), Interlaminar Fatigue Crack Growth In Carbon Fiber Reinforced Composites, The19th International Conference On Composite Materials, 1-9.

15. Szekrenyes A. (2010), Crack Stability of Fractuer Specimens Used to Test Unidirectional Fiber Reinforced Material, Experimental chanics, 50, 473-482.

The work has been accomplished under the research project TEBUK financed by the National Centre for Research and Development and the European Regional Development Fund. 